\title{
Effect of unintended pregnancy on skilled antenatal care uptake in Bangladesh: analysis of national survey data
}

\author{
Md Nuruzzaman Khan ${ }^{1,2^{*}}$, Melissa L. Harris ${ }^{3}$, Christopher Oldmeadow ${ }^{3}$ and Deborah Loxton ${ }^{3}$
}

\begin{abstract}
Background: Around $48 \%$ of all pregnancies in low- and middle-income countries are unintended. Unintended pregnancy may contribute to lower use of antenatal care (ANC); however, current research in the area is largely inconclusive due to the methodological approaches applied.

Methods: Responses from 4493 women extracted from the 2014 Bangladesh Demographic and Health Survey (BDHS) were used to assess the association between unintended pregnancy and subsequent uptake of at least one and at least four skilled ANC visits. For this, Bayesian multilevel logistic regression models with informative priors (representing a range of values within which the researcher is certain the true effect of the parameters included lies) were used, adjusting for other factors that affect ANC uptake. Informative priors were selected from the BDHS data collected in 2004, 2007, and 2011.
\end{abstract}

Results: Around 64\% of women in Bangladesh who had at least one pregnancy within 3 years prior to the survey (that ended in a live birth) received ANC at least once, and of these around 32\% used ANC at least four times. Mistimed (aOR, 0.73, 95\% Cred I, 0.66-0.81) and unwanted (aOR, 0.69, 95\% Cred I, 0.64-0.75) pregnancy were associated with reduced odds of attending the recommended minimum of four skilled ANC visits compared with wanted pregnancy. These likelihoods were even lower for at least one skilled ANC visit among women with a mistimed (aOR, 0.59, 95\% Cred I, 0.53-0.65) or an unwanted pregnancy (aOR, 0.67, 95\% Cred I, 0.61-0.74) than women with a wanted pregnancy.

Conclusions: In Bangladesh, more than one-quarter of women who report an unintended pregnancy at conception and do not terminate the pregnancy are at high risk of not using ANC. It is important for policies to include women with unintended pregnancy in mainstream healthcare services. This will increase the use of ANC and reduce associated adverse consequences.

Keywords: Unintended pregnancy, Antenatal care uptake, Informative Bayesian approach, Multilevel logistic regression model, Bangladesh

\footnotetext{
*Correspondence: sumonrupop@gmail.com;

mdnuruzzaman.khan@uon.edu.au

${ }^{1}$ Department of Population Sciences, Jatiya Kabi Kazi Nazrul Islam University,

Mymensingh, Bangladesh

${ }^{2}$ Priority Research Centre for Generational Health and Ageing, Faculty of

Health and Medicine, School of Medicine and Public Health, University of

Newcastle, Newcastle, Australia

Full list of author information is available at the end of the article
}

(c) The Author(s). 2020 Open Access This article is licensed under a Creative Commons Attribution 4.0 International License, which permits use, sharing, adaptation, distribution and reproduction in any medium or format, as long as you give appropriate credit to the original author(s) and the source, provide a link to the Creative Commons licence, and indicate if changes were made. The images or other third party material in this article are included in the article's Creative Commons licence, unless indicated otherwise in a credit line to the material. If material is not included in the article's Creative Commons licence and your intended use is not permitted by statutory regulation or exceeds the permitted use, you will need to obtain permission directly from the copyright holder. To view a copy of this licence, visit http://creativecommons.org/licenses/by/4.0/ The Creative Commons Public Domain Dedication waiver (http://creativecommons.org/publicdomain/zero/1.0/) applies to the data made available in this article, unless otherwise stated in a credit line to the data. 


\section{Background}

Increasing uptake of antenatal care (ANC) has been a long-term focus in low- and middle-income countries (LMICs) to improve maternal health and reduce maternal and child deaths [1]. This special interest is demonstrated by the high priority given to increasing ANC uptake in programs run by LMIC governments (e.g. Community-Based Health Planning and Services Programs in Ghana, Maternal and Child Health Care Programs in Bangladesh) and their collaborative programs with donor agencies (e.g. Sahel Women's Empowerment and Demographic Dividend, 2014, Global Financing Facility, 2015) [2-4]. Additionally, the Millennium Development Goals (MDGs) between 2000 and 2015 had the key priority of increasing ANC uptake [2]. Accordingly, substantial progress has been made in the uptake of ANC, particularly in the MDG period (increased from only 1 in 4 women in 1990 to nearly 1 in 2 women in 2015) [5]. However, this is insufficient, as more than half of women living in LMICs do not receive any ANC during pregnancy, with significant within-country variations [6-10]. Consequently, around 303,000 maternal deaths, 2.6 million stillbirths, and 2.7 million newborn deaths occur in LMICs because of preventable causes related to pregnancy and childbirth [11]. Therefore, strengthening programs to increase ANC uptake is being prioritised in the coming decades and has been added as a target for LMICs to achieve Sustainable Development Goal 3 (SDG 3, 2015-2030), which focuses on reducing preventable maternal and under-five deaths [12].

Bangladesh has achieved remarkable progress in increasing ANC uptake following the implementation of the MDGs (27\% in 1993 to 64\% in 2014, of which 32\% received ANC at least four times), which could have contributed to a substantial reduction in maternal deaths (181 per 100,000 live births in 2014) and under-five deaths (36 per 1000 live births in 2014) [13, 14]. However, it remains a daunting challenge to further reduce maternal and under-five deaths and increase uptake of ANC (part of universal health coverage), which are targeted in the SDGs. Multiple factors have been hindering this process, indicating that a careful analysis of healthcare service use is warranted, along with additional comprehensive interventions around ANC uptake in Bangladesh as well as other LMICs [15]. So far, research has suggested that reductions of educational and wealth gradients in ANC uptake and ensuring an equal level of ANC utilization in rural and urban areas are major challenges [16-19]. Other frequently reported challenges to increasing ANC utilization are as follows: high parity of women, lower autonomy to visit healthcare centres, lower exposure to healthcare services messages and consequent less knowledge regarding the importance of ANC uptake, and unemployment or being engaged in a marginal job $[16,17,20,21]$.

Around half of all pregnancies in LMICs, including Bangladesh, are unintended [22]. Of these, 55\% are ended by abortion, which results in one maternal death every $8 \mathrm{~min}$ and 5 million women suffering long-term health complications [22, 23]. Complications during and following delivery are also common among women having continued unintended pregnancies and is a major cause of maternal $[22,23]$, neonatal, and infant deaths in LMICs [24-26]. A global estimate by the Guttmacher Institute found that around a 92\% reduction in these deaths could be made by ensuring maternal healthcare services utilization (including ANC uptake) [27]. This indicates a need to explore the pattern of ANC use among women who have an unintended pregnancy and could be considered as critical to the speedy achievement of SDG 3 in LMICs and Bangladesh. However, studies with a major focus on this crucial subject are limited and findings are inconclusive. For instance, an analysis found that women in 32 LMICs who had an unintended pregnancy used ANC around 24\% less than women with a wanted pregnancy [21]. Subgroup analysis of these women across regions of countries found similar negative effects for sub-Saharan Africa and Latin America, while no effect was reported for Asia [21]. Conversely, country-level research in sub-Saharan Africa found highly inconsistent results with no $[6,7,28]$ or negative effects of unintended pregnancy on ANC uptake [2931]. Studies in Asian countries, including India and Bangladesh, found negative effects of unintended pregnancy on adequate (at least four visits) ANC [24, 32]. Meanwhile, a recent study in Bangladesh found no evidence of an association between unintended pregnancy and ANC uptake and reported that socio-demographic determinants and socio-economic inequality were major contributors to inadequate ANC uptake [8]. There are several factors that might lead to such disagreements, including different healthcare policies across countries and use of single-level analysis techniques with a limited number of confounders [21, 24, 28, 33].

One of the main reasons for such differing results is related to the methodological approaches applied. All studies were conducted to test the hypothesized association between unintended pregnancy and ANC uptake; however, they ignored the available knowledge (i.e. the sort of association found in previous research) regarding this association. Importantly, incorporating this knowledge in the model would help researchers run more stable models to identify the nature of the true relationship. Moreover, the previously conducted research, particularly in Bangladesh, considered a limited number of confounders and ignored the hierarchy of the data, such as individuals nested within households and households 
nested within communities. The Bayesian approach with multilevel modelling allows researchers to incorporate available knowledge in the model, along with considering the hierarchy of the data.

In order to determine whether unintended pregnancy is a true challenge to ANC uptake, it is important to identify the nature and strength of any association between pregnancy intention and services use. Consequently, this study was conducted to assess the association between unintended pregnancy and ANC uptake after adjusting for other factors that affect ANC uptake through the Bayesian multilevel logistic regression models with informative priors.

\section{Methods}

\section{Study overview}

The dataset used for this study was the nationally representative cross-sectional 2014 Bangladesh Demographic and Health Survey (BDHS). The National Institute of Population Research and Training (NIPROT) in Bangladesh conducted this survey as part of the Demographic and Health Survey (DHS) program. Financial and technical support was provided by the United States Agency for International Development (USAID). The Bangladesh government and the DHS institutional review board provided scientific clearance and authorization to conduct this survey. Data were collected by using twostage cluster sampling. A total of 600 enumeration areas (clusters) were selected in the first stage from the National Population and Housing Census sampling frame, with the probability of selection proportional to the unit size [13]. At the second stage, 30 households were selected within each primary sampling unit with systematic random sampling applied. Further details about sampling and other related issues of the BDHS can be found elsewhere [13].

\section{Sample}

We analysed data from 4493 women selected from all 600 clusters included in BDHS, 2014. The criteria used for inclusion in this study were i) gave birth at least once within 3 years preceding the survey and ii) responded to questions on pregnancy intention and ANC visits.

\section{Outcome variables}

ANC uptake was the outcome variable, categorized as at least one skilled ANC visit and at least four skilled ANC visits (WHO's recommendation at the time of the survey) $[34,35]$. Each surveyed woman who had given birth within 3 years preceding the date of interview was asked about whether she received any ANC during her pregnancy. Women who responded positively to this item were asked about the sources and number of times they received ANC. Responses were then categorized as follows: i) uptake of at least one skilled ANC visit (' 0 ' if she had no ANC visit from skilled health personnel, ' 1 ' otherwise); and ii) uptake of at least four skilled ANC visits (' 0 ' if she had fewer than four ANC visits from skilled health personnel, ' 1 ' otherwise). We considered qualified doctors, nurses/midwives/paramedics, family welfare visitors, community skilled birth attendants, and sub-assistant community medical officers as skilled health personnel, following the classification used in BDHS 2014 [13].

\section{Exposure variables}

The main exposure variable was pregnancy intention based on a woman's feelings at the time of conception about her most recent pregnancy which ended in a live birth. Pregnancy intention was categorized as either wanted (a pregnancy that was planned and desired), mistimed (a pregnancy that was wanted but occurred earlier than desired), or unwanted (a pregnancy that occurred when no children were desired).

Exposure variables that were considered as confounders of the association between pregnancy intention and ANC uptake were first identified by reviewing previous relevant literature published about ANC uptake in LMICs and Bangladesh [6-9, 21, 28, 30, 31, 36]. The variables identified were then tested for their level of associations with at least one skilled ANC visit and at least four skilled ANC visits. Variables found to be significant $(p=0.20)$ were then summarized using the socioecological model of health in three hierarchical levels: individual level, household/family level, and community level [37]. At the individual level, women's age at delivery (categorised as $\leq 19$ years, 20-34 years, and $\geq 35$ years), women's educational status (illiterate, primary, secondary, and higher), and quality of available ANC (treated as a continuous variable) were included. Total number of children ever born ( $\leq 2$ and $>2$ ), husband's education (illiterate, primary, secondary, and higher), husband's occupation (agricultural worker, physical labourer, service worker, business person, and other), index of exposure to mass media (non-exposed, moderately exposed, and highly exposed), and household wealth index (poorest, poorer, middle, richer, and richest) were included as household/family-level factors. Women's response to the questions related to the frequency of reading newspapers, listening to the radio, and watching television in a week were used to generate the index of exposure to mass media, following previous studies in Bangladesh [38, 39]. Women were classified as having no exposure to mass media if they did not access any of the three media at least once a week; as having moderate exposure to mass media if they accessed any of these media at least once a week, and as having high exposure to mass media if they accessed all three media at least once a week. Community-level factors that were 
considered in the analysis were the place of residence (urban and rural), region of residence (Barishal, Chattogram, Dhaka, Khulna, Rajshahi, Rangpur, and Sylhet), community-level literacy ( $\leq 25 \%, 26-50$, and $>50 \%)$, community-level poverty (high, moderate, low, and middle-to-richest), and community-level uptake of at least four ANC visits (>50\% and $\leq 50 \%$ ). These variables were categorized following previous studies in Bangladesh [40, 41]. Women's responses to the questions related to literacy, poverty, and ANC use across clusters were used to generate community-level responses on literacy, poverty, and ANC use, which were not directly available in the dataset used.

\section{Statistical analysis}

We summarised the demographic profile of the eligible women of the 2014 study using means and standard deviations. The proportion of women with at least one skilled ANC visit, the proportion of women with at least four skilled ANC visits, and the proportion of each pregnancy intention (wanted, mistimed, and unwanted) were reported with 95\% confidence intervals. Chi-square tests were used to assess the significance of the exposure variables with at least one skilled ANC visit and at least four skilled ANC visits. Multilevel logistic regression models with informative Bayesian approach were then used to assess the association between pregnancy intention (wanted, mistimed, and unwanted) and uptake of i) at least one skilled ANC visit and ii) at least four skilled ANC visits. The advantages of using this methodology have been described in detail elsewhere [42, 43]. Briefly, the model estimates the posterior probability distribution of parameters (for example, the odds ratio for the effect of pregnancy intention on at least one skilled ANC visit) by combining informative prior information (in the form of a distribution representing a range of plausible values) with the likelihood of the current data. Informative prior distribution of the regression coefficients were constructed by first fitting separate Bayesian multilevel logistic regression models with noninformative priors $($ mean $=0$, variance $=10,000)$ to each of the 2004, 2007 and 2011 BDHSs. We then modelled this prior distribution as independent normal distributions (one for each coefficient) in the proposed model, with means equal to the average of the previous year's regression coefficient and variance equal to the square of the regression coefficient standard deviation. Multilevel mixed-effects logistic regression models were used to estimate the maximum likelihood estimators. These were then used to estimate posterior distribution using the Markov Chain Monte Carlo (MCMC) method. We ran three different models separately for the uptake of at least one skilled ANC visit and uptake of at least four skilled ANC visits. Model 1 incorporated individual- and household-level factors, while Model 2 incorporated only community-level factors to present the different effects of individual-, household-, and community-level factors on uptake of at least one skilled ANC visit and uptake of at least four skilled ANC visits. We considered individual- and household-level factors together because of their strong correlation and because the average number of women per household in the BDHS was small, so household measures could not be analysed separately. Model 3 was the final model and included individual-, household-, and community-level factors. An additional model run was a null model, estimating intra-class correlation (ICC), which measured overall variation in least one skilled ANC visit and uptake of at least four skilled ANC visits. We used the Gelman-Rubin convergence diagnostic test to check the convergence of the MCMC method, which fits well and provided evidence of the accuracy of the analysis. All analyses were conducted taking into consideration the complex structure of the BDHS data and the survey weight. The posterior distributions are summarised and reported as odds ratios (ORs) with 95\% credible intervals (95\% Cred.I). Stata version 15.1 (Stata Corp, College Station, Texas, USA) was used to perform all statistical analyses.

\section{Results}

A total of 17,863 women completed the 2014 BDHS (the most recent survey), of which 4493 gave birth within 3 years prior to the survey and responses to the questions on ANC uptake and pregnancy intention were included in the analysis. Table 1 shows the background characteristics of the women. The mean age at most recent delivery was $23.6( \pm 5.7)$ years and the mean years of education was $6.3( \pm 3.8)$ years. Around one-quarter of all pregnancies that occurred within the preceding 3 years of the survey were unintended (26.0\%), of which $15.1 \%$ were reported as mistimed and $10.9 \%$ were reported as unwanted. Around $64 \%$ of women reported having at least one skilled ANC visit during their last pregnancy, of which $31.5 \%$ reported uptake of the recommended minimum four skilled ANC visits.

Figure 1 shows the proportion of women who took up at least one and four skilled ANC visits according to the pregnancy intention regarding their last child. Around $67 \%$ of women who had a wanted pregnancy reported attending at least one skilled ANC visit. This was higher than women who had a mistimed pregnancy $(57.8 \%)$ and women who had an unwanted pregnancy (52.6\%). Furthermore, a higher proportion of women who had a wanted pregnancy (34.3\%) met the four or more ANC visit target, followed by women who had a mistimed pregnancy $(27 \%)$ and women who had an unwanted pregnancy $(17.6 \%)$. 
Table 1 Background characteristics of the study population, BDHS 2014 (weighted sample $N=4493$ )

\begin{tabular}{lll}
\hline Characteristics & Subject (N) & Estimates (mean \pm SD or proportion $\mathbf{( 9 5 \%}$ Cl)) \\
\hline Age at most recent birth given, years & 4493 & $23.6(5.7)$ \\
Education, years & 4493 & $6.3(3.8)$ \\
Total number of children & 4493 & $2.16(1.4)$ \\
Engagement in formal employment & 4493 & $23.9(21.6-25.9)$ \\
Pregnancy intention (most recent birth) & & \\
$\quad$ Wanted & 3362 & $74.1(71.3-76.7)$ \\
$\quad$ Unintended & & $26.0(23.3-28.8)$ \\
$\quad$ Mistimed & 670 & $15.1(13.4-16.8)$ \\
$\quad$ Unwanted & 461 & $10.9(9.4-12.6)$ \\
Antenatal care services visit & & $63.8(60.4-67.1)$ \\
$\quad$ At least one visit & 2927 & $31.5(28.8-34.5)$ \\
Four or more visits & 1188 & \\
\hline
\end{tabular}

Uptake of at least one skilled ANC visit and at least four skilled ANC visits across selected individual-, household-, and community-level factors are presented in Table 2. Both at least one skilled ANC visit and at least four skilled ANC visits were found to be higher among women aged 20-34 years at the time of giving birth, women not engaged in any jobs, women of low socio-economic status, and women residing in Dhaka division. Primary and secondary educated women reported a higher uptake of at least one skilled ANC visit compared to higher educated women. In contrast, secondary educated women reported a higher uptake of at least four skilled ANC visits.

Of the four models run separately for at least one skilled ANC visit and at least four skilled ANC visits, the models convergence $\left(R_{c}\right)$ were compared. We also compared the AIC (Akaike information criterion), BIC (Bayesian information criterion), and ICC (Intra-class correlation) values to select the best model. The preferred model is the one which has the smaller model convergence $\left(R_{c}\right)$, AIC, BIC and ICC value (Table 3; Supplementary Tables 1 and 2). According to these markers, Model 4 (which included individual-, household-, and community-level factors) fitted the data better for each of the outcomes. The ICC values for the null model (Model 1) suggested that around 32 and $72 \%$ differences of using at least one skilled ANC visit and at least four skilled ANC visits, respectively, across clusters included in this study. These values were reduced to $1.70 \mathrm{e}-17$ and $60 \%$ for at least one skilled ANC visit and at least four skilled ANC visits, respectively, once individual-, household-, and community-level factors were adjusted for in the final model (Supplementary Tables 1 and 2; Table 3).

Odds ratios of both outcome variables produced in the final model (Model 4) are presented in Table 3, whereas all model results are presented in Supplementary

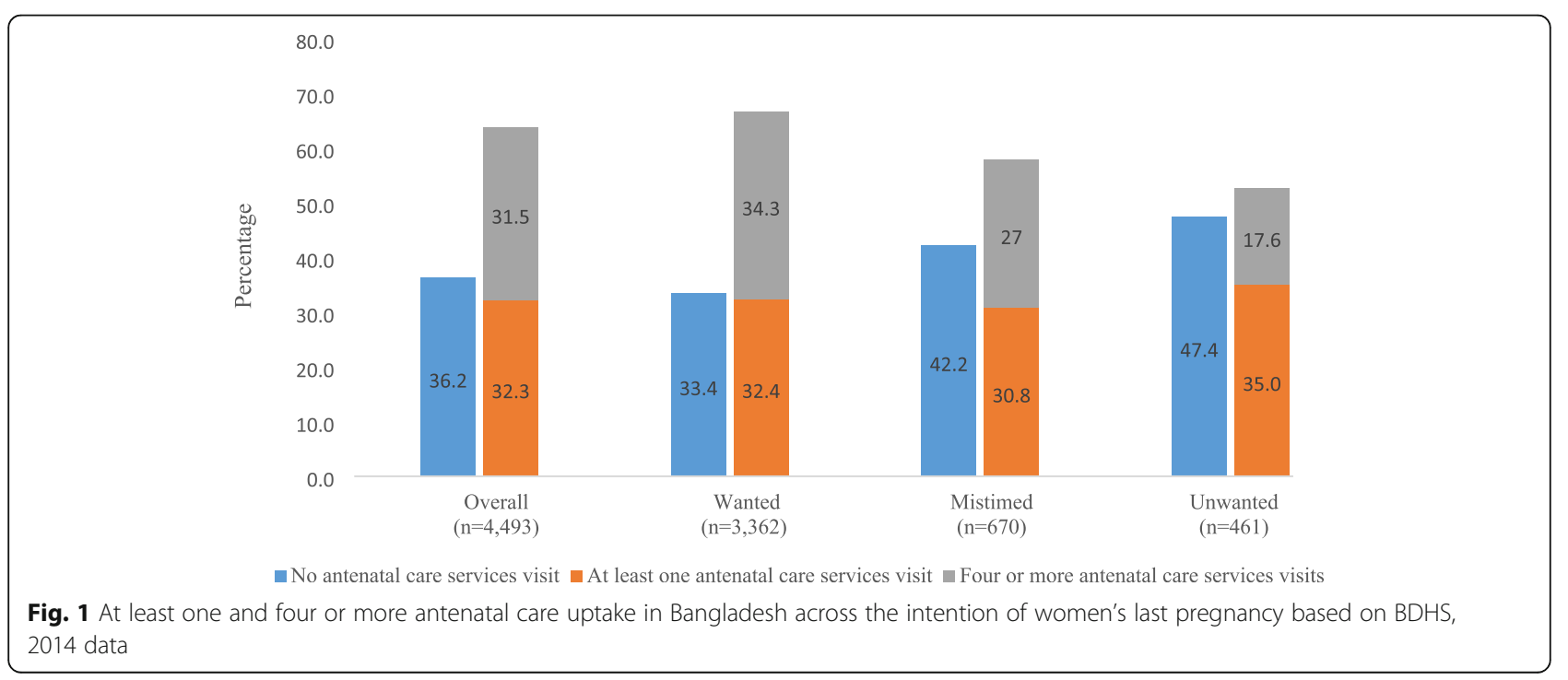


Table 2 Uptake of at least one skilled antenatal care visit and at least four skilled antenatal care visits, by selected characteristics, 2014 BDHS (weighted sample $N=4493$ )

\begin{tabular}{|c|c|c|c|c|}
\hline \multirow[t]{2}{*}{ Characteristics } & \multicolumn{4}{|l|}{ Prevalence ( $95 \%$ confidence interval) } \\
\hline & $\begin{array}{l}\text { At least one skilled antenatal care } \\
(n=2927)\end{array}$ & $p$-value & $\begin{array}{l}\text { Four and more skilled antenatal care } \\
(n=1188)\end{array}$ & $p$-value \\
\hline Pregnancy intention & & $p<0.01$ & & $p<0.01$ \\
\hline Wanted & $49.3(45.6-52.8)$ & & $25.9(23.0-19.0)$ & \\
\hline Mistimed & $8.7(7.8-9.7)$ & & $3.9(3.2-4.8)$ & \\
\hline Unwanted & $5.8(5.0-6.7)$ & & $1.8(1.1-2.7)$ & \\
\hline \multicolumn{5}{|l|}{ Women education } \\
\hline No education & $5.5(4.7-6.5)$ & $p<0.01$ & $1.6(1.0-2.6)$ & $p<0.01$ \\
\hline Primary & $14.4(13.2-15.8)$ & & $4.9(4.0-5.9)$ & \\
\hline Secondary & $3.5(31.9-37.4)$ & & $17.8(15.7-20.1)$ & \\
\hline Higher & $9.2(8.1-10.6)$ & & $7.3(6.2-8.5)$ & \\
\hline Women age birth (years) & & $p<0.05$ & & $p<0.05$ \\
\hline$\leq 19$ & $17.9(16.1-19.8)$ & & $8.3(7.0-9.8)$ & \\
\hline $20-34$ & $43.3(40.8-45.8)$ & & $22.2(20.1-24.5)$ & \\
\hline$\geq 35$ & $2.6(2.0-3.2)$ & & $1.1(0.7-1.5)$ & \\
\hline Women's working status & & 0.783 & & 0.215 \\
\hline Yes & $49.7(43.7-55.8)$ & & $28.1(25.5-30.9)$ & \\
\hline No & $50.6(47.4-53.7)$ & & $24.3(19.2-30.2)$ & \\
\hline Husband educational status & & $p<0.01$ & & \\
\hline No education & $10.2(9.1-11.4)$ & & $3.0(2.4-3.9)$ & $p<0.01$ \\
\hline Primary education & $16.7(14.9-18.7)$ & & $6.5(5.3-7.8)$ & \\
\hline Secondary education & $23.9(21.9-26.1)$ & & $12.5(10.1-14.4)$ & \\
\hline Higher education & $12.9(11.4-14.5)$ & & $9.6(8.2-11.1)$ & \\
\hline Husband occupation & & $p<0.01$ & & \\
\hline Agricultural workers & $12.2(10.6-13.9)$ & & $4.4(3.4-5.5)$ & $p<0.01$ \\
\hline Physical labourer & $28.9(26.4-31.1)$ & & $14.2(12.7-15.9)$ & \\
\hline Service worker & $5.2(4.3-6.2)$ & & $4.2(3.3-5.2)$ & \\
\hline Business person & $15.8(14.4-17.3)$ & & $7.7(6.6-9.0)$ & \\
\hline Others & $2.0(1.4-2.9)$ & & $1.1(0.5-2.1)$ & \\
\hline \multicolumn{5}{|l|}{ Children ever born } \\
\hline$\leq 2$ & $47.9(44.5-51.3)$ & $p<0.01$ & $25.6(22.9-28.6)$ & $p<0.01$ \\
\hline$>2$ & $15.9(14.6-17.2)$ & & $5.9(5.0-7.0)$ & \\
\hline \multicolumn{5}{|l|}{ Exposure to mass media } \\
\hline Not exposed & $17.5(15.8-19.3)$ & $p<0.01$ & $5.0(4.1-6.2)$ & $p<0.01$ \\
\hline Moderately exposed & $34.3(31.8-36.8)$ & & $17.6(15.8-19.4)$ & \\
\hline Highly exposed & $12.0(10.5-13.6)$ & & $9.0(7.6-10.5)$ & \\
\hline \multicolumn{5}{|l|}{ Wealth status } \\
\hline Poorest & $7.7(6.6-8.9)$ & $p<0.01$ & $1.9(1.5-2.6)$ & $p<0.01$ \\
\hline Poorer & $10.6(9.4-11.8)$ & & $3.4(2.7-4.3)$ & \\
\hline Middle & $12.3(11.1-13.7)$ & & $4.5(3.7-5.4)$ & \\
\hline Richer & $15.5(13.7-17.4)$ & & $8.7(7.4-10.1)$ & \\
\hline Richest & $17.7(15.5-20.2)$ & & $13.1(11.1-15.3)$ & \\
\hline \multicolumn{5}{|l|}{ Place of residence } \\
\hline Urban & $20.5(18.4-22.8)$ & $p<0.01$ & $13.6(11.8-15.6)$ & $p<0.01$ \\
\hline
\end{tabular}


Table 2 Uptake of at least one skilled antenatal care visit and at least four skilled antenatal care visits, by selected characteristics, 2014 BDHS (weighted sample $N=4493$ ) (Continued)

\begin{tabular}{|c|c|c|c|c|}
\hline \multirow[t]{2}{*}{ Characteristics } & \multicolumn{4}{|l|}{ Prevalence ( $95 \%$ confidence interval) } \\
\hline & $\begin{array}{l}\text { At least one skilled antenatal care } \\
(n=2927)\end{array}$ & p-value & $\begin{array}{l}\text { Four and more skilled antenatal care } \\
(n=1188)\end{array}$ & $p$-value \\
\hline Rural & $43.2(40.5-46.0)$ & & $18.0(15.9-20.2)$ & \\
\hline \multicolumn{5}{|l|}{ Region of residence } \\
\hline Barishal & $3.4(2.6-4.3)$ & $p<0.05$ & $1.5(1.0-2.2)$ & $p<0.05$ \\
\hline Chattogram & $14.4(12.4-16.7)$ & & $6.3(5.1-7.8)$ & \\
\hline Dhaka & $22.7(20.8-24.7)$ & & $12.0(10.3-14.1)$ & \\
\hline Khulna & $5.9(5.1-6.8)$ & & $3.3(2.6-4.2)$ & \\
\hline Rajshahi & $6.4(5.5-7.5)$ & & $2.9(2.3-3.8)$ & \\
\hline Rangpur & $6.1(5.1-7.2)$ & & $3.5(2.8-4.4)$ & \\
\hline Sylhet & $4.9(3.7-6.5)$ & & $2.0(1.4-3.0)$ & \\
\hline Community-level literacy & & $p<0.01$ & & $p<0.01$ \\
\hline Low $(\leq 25 \%)$ & $7.0(5.3-9.2)$ & & $1.7(1.2-2.5)$ & \\
\hline Moderate (26-50\%) & $30.1(26.7-33.9)$ & & $14.4(12.3-16.7)$ & \\
\hline High (> 50\%) & $26.6(22.7-31.0)$ & & $15.5(12.8-18.5)$ & \\
\hline \multicolumn{5}{|l|}{ Community-level poverty ${ }^{+}$} \\
\hline High & $5.3(3.4-7.3)$ & $p<0.01$ & $2.7(1.7-4.3)$ & $p<0.01$ \\
\hline Moderate & $16.8(13.8-20.3)$ & & $7.3(5.9-9.1)$ & \\
\hline Low & $22.6(19.6-25.8)$ & & $8.4(6.9-10.3)$ & \\
\hline Middle-to-richest & $19.4(16.4-22.8)$ & & $13.2(10.9-15.9)$ & \\
\hline \multicolumn{5}{|c|}{ Community-level at least four skilled antenatal care visits } \\
\hline High (> 50\%) & $39.1(36.7-41.6)$ & $p<0.01$ & $16.9(15.1-18.9)$ & $p<0.01$ \\
\hline Low $(\leq 50 \%)$ & $24.7(22.5-27.1)$ & & $14.7(12.0-17.9)$ & \\
\hline
\end{tabular}

Note: "Women living in a community consisting of only women in the top three wealth quintiles were categorized as living in a "middle-to-richest" community; all other women were categorized on the basis of the proportion of household in their community in the lowest two wealth quintiles: low (25\%), moderate (26-50\%) and high (>50\%)

Tables 1 and 2. A 27\% (95\% Cred. I, 0.66-0.81) and a 31\% (95\% Cred. I, 0.64-0.75) lower odds of attending at least four skilled ANC visits were found among women who had a mistimed and an unwanted pregnancy, respectively, compared to women who had a wanted pregnancy. These likelihoods were even lower for at least one skilled ANC visit among women who had a mistimed pregnancy (aOR, 0.59, 95\% Cred. I, 0.53-0.65) and women who had an unwanted pregnancy (aOR, 0.67, 95\% Cred. I, 0.61-0.74) than women who had a wanted pregnancy.

A number of confounders that were adjusted for were also found to be preventive of having at least one skilled ANC visit and at least four skilled ANC visits. These were women and their husbands who had a lower education, higher number of births, lower quality of available ANC, less exposure to mass media, and lower household wealth. Higher likelihoods of having at least one skilled ANC visit were found among women aged 20 -34 years and $\geq 35$ years than their counterparts aged $\leq 19$ years. However, the likelihood of having four or more skilled ANC visits was found to be lower among women aged 20-34 years.

Lower likelihoods of ANC uptake were found among women who lived rurally and women who resided in Chattogram region compared to women who lived in an urban area and women who resided in Barishal region. Higher likelihoods of having at least one skilled ANC visit as well as four or more skilled ANC visits were found among women who resided in Khulna, Rangpur, and Sylhet regions. Women who resided in communities with moderate and higher literacy were reported to have around a $40 \%$ higher uptake of four or more skilled ANC visits than women residing in a community with low literacy. Lower likelihoods uptake of ANC visit (both at least one and at least four) were also found among women residing in the middle-to- richest communities than their counterparts residing in communities with higher poverty. Compared to the higher communitylevel uptake of four or more skilled ANC visits (at least $50 \%$ of community people), lower community-level uptake of at least four skilled ANC visits $(<50$ of 
Table 3 Multilevel modelling with Bayesian informative approach to determine the associated with at least one skilled antenatal care uptake and four or more skilled antenatal care uptake in Bangladesh for the year 2014 (using 2014 BDHS)

\begin{tabular}{|c|c|c|}
\hline & $\begin{array}{l}\text { At least one skilled antenatal care uptake, } \\
\text { aOR }(95 \% \text { Cred. I) }\end{array}$ & $\begin{array}{l}\text { Four or more skilled antenatal care uptake, } \\
\text { aOR }(95 \% \text { Cred. I) }\end{array}$ \\
\hline \multicolumn{3}{|c|}{ Most recent pregnancy: wanted (ref) } \\
\hline Mistimed pregnancy & $0.59(0.53-0.65)$ & $0.73(0.66-0.81)$ \\
\hline Unwanted pregnancy & $0.67(0.61-0.74)$ & $0.69(0.64-0.75)$ \\
\hline \multicolumn{3}{|c|}{ Women's education: illiterate (ref) } \\
\hline Primary & $1.66(1.39-1.94)$ & $0.97(0.91-1.03)$ \\
\hline Secondary & $1.88(1.61-2.12)$ & $1.21(1.10-1.33)$ \\
\hline Higher & $1.25(1.11-1.41)$ & $1.85(1.71-2.00)$ \\
\hline \multicolumn{3}{|c|}{ Husband's education: illiterate (ref) } \\
\hline Primary & $1.00(0.91-1.09)$ & $1.42(1.29-1.55)$ \\
\hline Secondary & $1.25(1.12-1.41)$ & $1.60(1.48-1.73)$ \\
\hline Higher & $1.19(1.06-1.33)$ & $1.62(1.50-1.76)$ \\
\hline \multicolumn{3}{|c|}{ Total number of children ever born: $\leq 2$ (ref) } \\
\hline$>2$ & $1.04(0.91-1.22)$ & $0.79(0.71-0.86)$ \\
\hline \multicolumn{3}{|c|}{ Age at last birth given: $\leq 19$ (ref) } \\
\hline $20-34$ & $1.20(1.07-1.31)$ & $0.91(0.84-0.96)$ \\
\hline$\geq 35$ & $1.58(1.41-1.76)$ & $1.09(0.98-1.21)$ \\
\hline Quality of antenatal care & $0.9(0.08-0.10)$ & $0.40(0.38-0.41)$ \\
\hline \multicolumn{3}{|c|}{ Husband's occupation: agricultural worker (ref) } \\
\hline Physical labourer & $1.06(0.98-1.16)$ & $1.61(1.49-1.74)$ \\
\hline Services & $1.74(1.49-2.01)$ & $2.52(2.29-2.76)$ \\
\hline Business & $2.12(1.89-2.37)$ & $1.54(1.40-1.73)$ \\
\hline Others & $2.17(1.89-2.45)$ & $2.03(1.73-2.32)$ \\
\hline \multicolumn{3}{|c|}{ Exposure to mass media: not exposed (ref) } \\
\hline Moderately exposed & $0.91(0.79-1.04)$ & $1.09(1.00-1.18)$ \\
\hline Highly exposed & $0.92(0.82-1.01)$ & $1.21(1.15-1.27)$ \\
\hline \multicolumn{3}{|l|}{ Wealth status: poorest (ref) } \\
\hline Poorer & $3.31(2.80-3.81)$ & $1.44(1.27-1.65)$ \\
\hline Middle & $1.85(1.64-2.07)$ & $1.52(1.43-1.60)$ \\
\hline Richer & $1.71(1.48-1.98)$ & $1.53(1.38-1.69)$ \\
\hline Richest & $1.83(1.59-2.07)$ & $1.78(1.69-1.87)$ \\
\hline \multicolumn{3}{|l|}{ Place of residence: urban (ref) } \\
\hline Rural & $0.61(0.56-0.67)$ & $0.67(0.62-0.72)$ \\
\hline \multicolumn{3}{|c|}{ Region of residence: Barishal (ref) } \\
\hline Chattogram & $3.46(3.09-3.87)$ & $0.90(0.82-0.98)$ \\
\hline Dhaka & $2.50(2.12-2.93)$ & $0.98(0.92-1.05)$ \\
\hline Khulna & $2.69(2.29-3.14)$ & $1.20(1.11-1.31)$ \\
\hline Rajshahi & $4.20(3.61-4.82)$ & $1.15(0.98-1.33)$ \\
\hline Rangpur & $3.65(3.12-4.20)$ & $1.10(1.02-1.18)$ \\
\hline Sylhet & $3.00(2.75-3.27)$ & $1.15(1.08-1.23)$ \\
\hline \multicolumn{3}{|c|}{ Community-level literacy: low ( $\leq 25 \%$, ref) } \\
\hline Moderate (25-50\%) & $0.86(0.75-0.99)$ & $1.37(1.28-1.47)$ \\
\hline High (> 50\%) & $1.04(0.92-1.17)$ & $1.42(1.28-1.59)$ \\
\hline
\end{tabular}


Table 3 Multilevel modelling with Bayesian informative approach to determine the associated with at least one skilled antenatal care uptake and four or more skilled antenatal care uptake in Bangladesh for the year 2014 (using 2014 BDHS) (Continued)

\begin{tabular}{lll}
\hline & $\begin{array}{l}\text { At least one skilled antenatal care uptake, } \\
\text { aOR (95\% Cred. I) }\end{array}$ & $\begin{array}{l}\text { Four or more skilled antenatal care uptake, } \\
\text { aOR (95\% Cred. I) }\end{array}$ \\
\hline Moderate (25-50\%) & $1.24(1.07-1.42)$ & $0.94(0.85-1.03)$ \\
Low $(<25 \%)$ & $1.41(1.22-1.63)$ & $0.97(0.88-1.08)$ \\
Middle-to- richest & $0.67(0.61-0.75)$ & $0.86(0.78-0.95)$ \\
Community-level at least four skilled antenatal care visits $(>50 \%)$ & \\
Low $(<50 \%)$ & $0.78(0.70-0.87)$ & $0.19(0.18-0.0 .20)$ \\
Constant & $2.81(2.50-3.14)$ & $0.36(0.33-0.39)$ \\
Intra-class correlation (ICC, cluster level) & $1.70 \mathrm{e}-17$ & 0.60 \\
AIC & 3455.26 & 3455.25 \\
BIC & 3689.52 & 3689.52 \\
\hline
\end{tabular}

Note: Ref reference group, aOR Adjusted Odds Ratio, Cred. I Credible Interval, estimates were based on informative Bayesian approach with multilevel logistic regression modelling. An informative prior distribution for the regression coefficients was constructed by first fitting separate Bayesian multilevel logistic regression models with non-informative priors (mean $=0$, variance $=10,000$ ) to each of the 2004, 2007 and 2011 BDHSs; AIC, Akaike Information Criterion; BIC, Bayesian Information Criterion; ICC, Intra-class correlation. ${ }^{+}$Women living in a community consisting of only women in the top three wealth quintiles were categorized as living in a "middle-to-richest" community; all other women were categorized on the basis of the proportion of household in their community in the lowest two wealth quintiles: low (25\%), moderate (26-50\%) and high (>50\%). To see the results for each model, see supplementary Tables 1 and 2

community people) was also found to be significant to lowered odds of having four or more skilled ANC visits.

\section{Discussion}

The primary aim of this study was to provide empirical evidence for the association between pregnancy intention and subsequent ANC uptake using nationally representative household survey data from Bangladesh. Around one-quarter of all pregnancies that ended in live births within 3 years preceding the survey were unintended. There were around 27 and 31\% lower likelihoods of having the recommended minimum four skilled ANC visits among women who had a mistimed pregnancy and women who had an unwanted pregnancy, respectively, compared to women who had a wanted pregnancy. Likelihoods were even lower for at least one skilled ANC visit, with women who had a mistimed pregnancy and women who had an unwanted pregnancy reporting 41 and 33\% lower odds of having at least one skilled ANC visit, respectively, than women who had a wanted pregnancy. This indicates the risk of increasing adverse consequences (e.g. maternal and child deaths) associated with no or lower ANC uptake. Policies are required for the early detection of women who have unintended pregnancies through family planning workers and adding them to mainstream healthcare services.

The SDGs call for universal health coverage and the reduction of preventable maternal and under-five deaths in LMICs [12]. However, the provision of health coverage does not necessarily translate into actual uptake. Our study indicates that unintended pregnancy (at around 26\%) is a barrier to ANC uptake, and therefore, will challenge Bangladesh's ability to achieve its SDG targets. This finding is in line with previous studies in other LMICs, including Tanzania, Zimbabwe, and Brazil [29-31], although the actual prevalence of unintended pregnancy in Bangladesh is lower than other LMICs [22, 44, 45]. However, previous studies in Bangladesh reported no effects of a mistimed pregnancy [9] or an unintended pregnancy [8] on ANC uptake, compared to a wanted pregnancy.

The factors associated with lower likelihoods of ANC uptake following an unintended pregnancy are complex, making designing interventions challenging. A variety of factors related to the pregnancy, the woman and her partner, and psychological responses following pregnancy could be linked with lower likelihoods of ANC uptake [46]. For instance, a mistimed or an unwanted pregnancy are most often identified later than a wanted pregnancy [47], and delay in deciding whether to terminate the pregnancy [48] could result in less time to receive ANC. The characteristics of women and their partners (i.e. already having the desired number of children, and/or lower education and socio-economic status) who report higher unintended pregnancies could also reduce ANC uptake $[49,50]$. This link could be due to women's tendency to rely on experience gained from previous pregnancies, financial difficulties, lower awareness of ANC, autonomy to receive ANC, or some combination of these factors [21]. Moreover, women who have an unintended pregnancy may have psychological problems (e.g. depression, anxiety) that arise from less favourable behaviours, either from their partners, their family members, or both [46]. These are most often in addition to women's concern about adverse life events (e.g. problems related to work, education, and/or finances), which could prevent them from taking up ANC [51]. 
In Bangladesh, ANC services are available only in the pre-specified healthcare facilities [13], whose number is usually lower than the actual number of available healthcare facilities [52]. Previous assessments in LMICs found that availability of ANC only in the pre-specified healthcare facilities could reduce the overall uptake of ANC $[18,53,54]$. Given there is no health insurance coverage in Bangladesh, women have to depend mostly on their partners or family members to meet healthcare costs. Moreover, religious and socio-cultural customs in Bangladesh mostly restrict women's movements during pregnancy. This increases women's dependency on their partners and/or family members to accompany them to healthcare centres. Together, this contributes to lower uptake of ANC following an unintended pregnancy. The underlying causes are women's lower autonomy, and their partners/family members unfavourable behaviours as well as unwillingness or inability to expense travel money [46, 51]. These limitations are further amplified for women residing in rural areas and communities with higher illiteracy and poverty, where previous studies have found a higher occurrence of unintended pregnancy $[49,50]$. This is because rural areas have a limited number of healthcare facilities, services provided there are deemed lower in quality, and rural women face strong religious and/or cultural opposition to visiting healthcare facilities, particularly when the healthcare facility is far away [55-57]. Under these circumstances, early detection of women's pregnancy intention and provision of services at the community level are recommended to increase ANC uptake in Bangladesh [15].

Healthcare policies in Bangladesh have primarily been focused on providing free ANC for all women and on promoting media campaigns to substantially increase ANC uptake [58, 59]. However, these policies might be ineffective for women with an unintended pregnancy, as they are most often disadvantaged, among whom this study, as well as other studies in Bangladesh, have found higher odds of not utilizing ANC [8,9]. This, therefore, leads to multifaceted risk factors of not using ANC among women with an unintended pregnancy. For instance, disadvantageous socio-demographic and societal factors (which are mostly unchanged by the pregnancy experience) are often additional to the healthcare system-level factors and characteristics following the occurrence of an unintended pregnancy. This suggests a need for additional interventions.

Motivating women to use healthcare services could be an effective way to increase ANC uptake among women who have an unintended pregnancy [21]. However, this might not be possible in Bangladesh with the current two-level structure of the maternal healthcare system: maternal healthcare services (provided in clinics/healthcare centres/hospitals by the Directorate General of
Health Services [DGHS]) and family planning services (provided at the household level by the Directorate General of Family Planning Services [DGFS]). Therefore, such institution-based maternal healthcare services might not be effective to ensure ANC services use among women who do not visit healthcare centres or who do not continue visiting for ANC. A link between family planning workers and ANC providers in prespecified healthcare centres for ANC services should be developed to ensure that doorstep ANC is provided to the women who are not motivated to use ANC (because of distance, unintended pregnancy, or any other cause) [60]. This initiative needs a country-level approach to extend the role of maternal healthcare service providers to provide household-level services instead of the current structure of institutional-level services. Additional initiatives are also needed to upskill the current family planning service providers (in total 219,000 providers [56,000 in government sectors and 163,000 in non-government sectors]) to extend their roles to detecting women's pregnancy intention and ensuring maternal healthcare services use during each pregnancy [59, $61,62]$. Focus is also needed to alleviate the current shortage of family planning service providers $(800,000)$ to ensure they are present in each community, particularly in disadvantaged groups (in terms of ANC uptake and occurrence of unintended pregnancy) $[18,21,63]$.

The existing healthcare system in Bangladesh does not focus on religious or cultural norms, which are often barriers to ANC uptake, particularly in communities with higher illiteracy and poverty and where the occurrence of unintended pregnancy is higher [21, 64]. Importantly, these religious and cultural norms are often more influential than individual-level factors (e.g. poor autonomy, lower education), indicating current individual-level awareness programs on maternal healthcare services might not ensure universal uptake of ANC, which is a target in the SDGs. Therefore, at the community-level, community and religious leaders could be engaged to motivate women and increase awareness of ANC visits. Moreover, it is also important to decentralize healthcare centres, which are currently mainly situated in urban areas, to rural areas and resource-poor settings [13]. Furthermore, new healthcare centres are needed, particularly in Chattogram division, where uptake of ANC is usually found to be lower than other divisions in Bangladesh $[8,20]$. This is particularly important as illiteracy and poverty are higher in these settings, which increases unintended pregnancies and reduces ANC uptake [65]. The establishment of 18, 000 community health clinics in the sub-district level through a recently completed project (mostly in rural and resource-poor settings) made substantial progress in meeting this target [66]. However, additional policies are 
needed to ensure the provision of necessary physical and human infrastructure, logistics, and supplies, as well as policies to encourage women (particularly women at a higher risk of not receiving $\mathrm{ANC}$ ) to receive ANC, as existing healthcare centres have frequently been reported to be low-performing or underutilized [64].

The current study has a number of strengths. A major strength is that it analysed a nationally representative sample through informative Bayesian multilevel logistic regression models, which is considered a proper framework for healthcare services research. In addition to the appropriate adjustment of confounders, we calculated their informative priors from the earlier rounds of BDHSs (conducted in 2004, 2007, and 2011), which were identical (in terms of sampling and response rates) to BDHS 2014 that data analysed. This provides evidence on the validity of informative priors used, and therefore, odds estimated in this study are considered more precise and robust than the classical models. However, responses on pregnancy intention and ANC uptake were collected after delivery, hence could be subject to recall bias. Moreover, since the data were only collected from women who had live births, underreporting might have occurred because of pregnancy termination and the reporting of ambivalent responses on pregnancy intention. In addition, the association between women's pregnancy intention and subsequent use of ANC were adjusted for available individual-, household-, and community-level factors. The very low value of ICC for at least one skilled ANC visit (1.70e-17) suggested that confounders included can almost fully explain the cluster-level variation of attendance of at least one skilled ANC visit. However, a higher ICC value for four or more skilled ANC visits (0.60) suggested a need to adjust additional factors, including availability and accessibility of healthcare services and motivational factors. However, these factors were not included in the analysis because of the lack of data. Additionally, this study analysed data of the 2014 BDHS, which may be considered dated; however, no other nationally representative survey was conducted after this survey and no major changes to maternal healthcare polices or programs have occurred since this survey was conducted. Therefore, the results can still provide a benchmark for monitoring and evaluating current maternal healthcare services in Bangladesh.

\section{Conclusions}

The findings demonstrate that around two-thirds of women who gave birth in the 3 years preceding the survey received ANC at least once. However, four or more skilled ANC visits, as recommended by the WHO, was just $32 \%$ of women. These percentages of ANC uptake varied significantly across women's pregnancy intention at the time of conception. After adjustment for confounders, we found that having a mistimed and having an unwanted pregnancy were associated with lower odds of ANC uptake compared to having a wanted pregnancy. This suggests that unintended pregnancy (at around 26\%) challenges Bangladesh's ability to achieve its SDG targets of universal health coverage and of reducing preventable maternal and under-five deaths. Early detection of women's pregnancy intention and initiatives to include women in mainstream healthcare services are therefore important. This can be done by extending the role of family planning providers to detecting pregnancy intention and motivating women to receive ANC, as well as making them collaborate with ANC providers to prespecified healthcare centres for ANC services. Policies and programs focusing on religious and cultural norms are also important to successfully increasing ANC uptake, particularly among communities where illiteracy and poverty are higher.

\section{Supplementary information}

Supplementary information accompanies this paper at https://doi.org/10 1186/s13690-020-00468-1.

Additional file 1: Supplementary Table 1. Multilevel modelling with Bayesian informative approach to determine the associated with at least one skilled antenatal care visit in Bangladesh for the year 2014 (using 2014 BDHS). Supplementary Table 2. Multilevel modelling with Bayesian informative approach to determine the associated with at least four skilled antenatal care visits in Bangladesh for the year 2014 (using 2014 BDHS).

\section{Abbreviations}

ANC: Antenatal care; AIC: Akaike Information Criteria; BDHS: Bangladesh Demographic and Health Survey; BIC: Bayesian Information Criteria; ICC: Intraclass correlation; LMICs: Low- and Middle-Income Countries;

MDGs: Millennium Development Goals; OR: Odds Ratios; 95\% Cred I: 95\% Credible Interval; SDGs: Sustainable Development Goals; WHO: World Health Organization

\section{Acknowledgements}

We acknowledge the support of the Priority Research Centre for Generational Health and Ageing, a member of the Hunter Medical Research Institute, Australia, where this research was conducted.

\section{Authors' contributions}

MNK, MLH, and DL developed the study concept. MNK conducted the formal analysis. CO checked methods, analysis and results. MNK drafted the manuscript. MLH, CO, and DL critically reviewed the manuscript. All authors approved the final version of this manuscript.

\section{Funding}

The first author is supported by a PhD research scholarship from The University of Newcastle, Australia. Dr. Melissa L. Harris is supported by an Australian Research Council Discovery Early Career Researcher Award. None of the authors contributed any funds to support publication costs.

\section{Availability of data and materials}

The data that support the findings of this study are available from the DHS Program, but restrictions apply to the availability of these data, which were used under license for the current study, and so are not publicly available. Data are, however, available from the authors upon reasonable request and with permission of the DHS Program. 


\section{Ethics approval and consent to participate}

The survey protocol was reviewed and approved by the National Research Ethics Committee in Bangladesh and the MEASURE DHS, USA. Additional approval for analysing secondary data were granted by the University of Newcastle, Australia, Research Ethics Board.

\section{Consent for publication}

Not applicable.

\section{Competing interests}

None.

\section{Author details}

${ }^{1}$ Department of Population Sciences, Jatiya Kabi Kazi Nazrul Islam University, Mymensingh, Bangladesh. ${ }^{2}$ Priority Research Centre for Generational Health and Ageing, Faculty of Health and Medicine, School of Medicine and Public Health, University of Newcastle, Newcastle, Australia. ${ }^{3}$ Faculty of Health and Medicine, School of Medicine and Public Health, University of Newcastle, Newcastle, Australia.

Received: 26 February 2020 Accepted: 8 September 2020

Published online: 16 September 2020

\section{References}

1. Arsenault C, Jordan K, Lee D, Dinsa G, Manzi F, Marchant T, Kruk ME. Equity in antenatal care quality: an analysis of 91 national household surveys. Lancet Glob Health. 2018;6(11):e1186-95.

2. United Nation. The millennium development goals report, 2015. The United States of America: The United Nation New York; 2016.

3. Nyonator FK, Awoonor-Williams JK, Phillips JF, Jones TC, Miller RA. The Ghana community-based health planning and services initiative for scaling up service delivery innovation. Health Policy Plan. 2005;20(1):25-34.

4. The World Bank. Reproductive, Maternal, Newborn, Child, and Adolescent Health. Washington, DC: The World Bank; 2015. Access from https:// wwwworldbankorg/en/topic/reproductivematernalchildhealthon 08 June 2019.

5. Moller A-B, Petzold M, Chou D, Say L. Early antenatal care visit: a systematic analysis of regional and global levels and trends of coverage from 1990 to 2013. Lancet Glob Health. 2017;5(10):e977-83.

6. Dansereau E, McNellan CR, Gagnier MC, Desai SS, Haakenstad A, Johanns CK, Palmisano EB, et al. Coverage and timing of antenatal care among poor women in 6 Mesoamerican countries. BMC Pregnancy Childb. 2016;16(1): 234.

7. Saad-Haddad G, DeJong J, Terreri N, Restrepo-Méndez MC, Perin J, Vaz L, Newby $\mathrm{H}$, et al. Patterns and determinants of antenatal care utilization: analysis of national survey data in seven countdown countries. J Glob Health. 2016;6(1):010404.

8. Islam MM, Masud MS. Health care seeking behaviour during pregnancy, delivery and the postnatal period in Bangladesh: assessing the compliance with WHO recommendations. Midwifery. 2018;63:8-16.

9. Rahman MM, Rahman MM, Tareque MI, Ferdos J, Jesmin SS. Maternal pregnancy intention and professional antenatal care utilization in Bangladesh: a nationwide population-based survey. PLoS One. 2016;11(6): e0157760.

10. Kuhnt J, Vollmer S. Antenatal care services and its implications for vital and health outcomes of children: evidence from 193 surveys in 69 low-income and middle-income countries. BMJ Open. 2017;7(11):e017122.

11. World Health Organization. Trends in maternal mortality: 1990-2015: estimates from WHO, UNICEF, UNFPA, World Bank Group and the United Nations Population Division; 2015

12. United Nation. Sustainable Development Goal. The United States of America: The United Nation; 2015. Accessed from https://wwwunorg/ sustainabledevelopment/health/ on June, 2019.

13. National Institute of Population Research and Training (NIPORT), Mitra and Associates, and ICF International. Bangladesh Demographic and Health Survey 2014. Dhaka: National Institute of Population Research and Training (NIPORT); 2016.

14. Bangladesh Planning Commission. Millennium development goals: Bangladesh progress report-2015. Dhaka: General Economics Division (GED), Bangladesh Plannning Commission (BPC), Government of the People's Republic of Bangladesh; 2015.
15. El Arifeen S, Christou A, Reichenbach L, Osman FA, Azad K, Islam KS, Ahmed F, et al. Community-based approaches and partnerships: innovations in health-service delivery in Bangladesh. Lancet. 2013;382(9909):2012-26.

16. Khan $\mathrm{MMH}$, Krämer $\mathrm{A}$, Khandoker A, Prüfer-Krämer L, Islam A. Trends in sociodemographic and health-related indicators in Bangladesh, 1993-2007: will inequities persist? Bull World Health Organ. 2011;89:583-93.

17. Pulok MH, Sabah MN-U, Uddin J, Enemark U. Progress in the utilization of antenatal and delivery care services in Bangladesh: where does the equity gap lie? BMC Pregnancy Childb. 2016;16(1):200.

18. Abosse Z, Woldie M, Ololo S. Factors influencing antenatal care service utilization in hadiya zone. Ethiop J Health Sci. 2010;20(2):75-82.

19. Kanyangarara M, Munos MK, Walker N. Quality of antenatal care service provision in health facilities across sub-Saharan Africa: Evidence from nationally representative health facility assessments. J Glob Health. 2017;7(2):021101.

20. Kishowar HA. Utilization of antenatal care services in Bangladesh: an analysis of levels, patterns, and trends from 1993 to 2007. Asia Pac J Public He. 2010; 22(4):395-406.

21. Guliani H, Sepehri A, Serieux J. Determinants of prenatal care use: evidence from 32 low-income countries across Asia, sub-Saharan Africa and Latin America. Health Policy Plan. 2013;29(5):589-602.

22. Bearak J, Popinchalk A, Ganatra B, Moller A, Tunçalp Ö, et al. Unintended pregnancy and abortion by income, region, and the legal status of abortion: estimates from a comprehensive model for 1990-2019. Lancet Glob Health. 2020;8:e1152-61.

23. Haddad LB, Nour NM. Unsafe abortion: unnecessary maternal mortality. Rev Obstet Gynecol. 2009;2(2):122.

24. Singh A, Singh A, Mahapatra B. The consequences of unintended pregnancy for maternal and child health in rural India: evidence from prospective data. Matern Child Health J. 2013;17(3):493-500.

25. Mohllajee AP, Curtis KM, Morrow B, Marchbanks PA. Pregnancy intention and its relationship to birth and maternal outcomes. Obstet Gynecol. 2007; 109(3):678-86.

26. Assefa N, Berhane $Y$, Worku A, Tsui A. The hazard of pregnancy loss and stillbirth among women in Kersa, East Ethiopia: a follow up study. Sex Reprod Healthc. 2012;3(3):107-12.

27. Guttmacher Institute. Adding it up: investing in contraception and maternal and newborn health; 2017. Available at https://wwwguttmacherorg/factsheet/adding-it-up-contraception-mnh-2017.

28. Gupta S, Yamada G, Mpembeni R, Frumence G, Callaghan-Koru JA, Stevenson R, Brandes N, et al. Factors associated with four or more antenatal care visits and its decline among pregnant women in Tanzania between 1999 and 2010. PLoS One. 2014;9(7):e101893.

29. Exavery A, Kanté AM, Njozi M, Tani K, Doctor HV, Hingora A, Phillips JF. Predictors of mistimed, and unwanted pregnancies among women of childbearing age in Rufiji, Kilombero, and Ulanga districts of Tanzania. Reprod Health. 2014;11(1):63.

30. Bassani DG, Surkan PJ, Olinto MTA. Inadequate use of prenatal services among Brazilian women: the role of maternal characteristics. Int Perspect Sex Reprod Health. 2009;35(1):15-20.

31. Muchabaiwa L, Mazambani D, Chigusiwa L, Bindu S, Mudavanhu V. Determinants of maternal healthcare utilization in Zimbabwe. Int J Econ Sci Appl Res. 2012:5(2):145-62.

32. Rahman MM. Is unwanted birth associated with child malnutrition in Bangladesh? Int Perspect Sex Reprod Health. 2015;41(2):80-8.

33. Etzioni RD, Kadane JB. Bayesian statistical methods in public health and medicine. Annu Rev Public Health. 1995;16(1):23-41.

34. World Health Organization. New guidelines on antenatal care for a positive pregnancy experience. Geneva: The World Health Organization; 2016. Accessed from https://wwwwhoint/reproductivehealth/news/antenatalcare/en/ on 10 Jan 2019.

35. Bangladesh Government. Maternal health strategy of Bangladesh. Dhaka: Ministry of Health and Family Welfare; 2016.

36. Parkhurst JO, Penn-Kekana L, Blaauw D, Balabanova D, Danishevski K, Rahman SA, Onama V, et al. Health systems factors influencing maternal health services: a four-country comparison. Health Policy. 2005;73(2):127-38.

37. United Nations Children's Fund. Socio-ecological model of health: The United Nations Children's fund, Ney York, USA, 2013. Available at https:// www.uniceforg/cbsc/files/Module_1_SEM-C4Ddocx.

38. Khan MN, Kumar P, Rahman MM, Islam Mondal MN, Islam MM. Inequalities in utilization of maternal reproductive health Care Services in Urban Bangladesh: a population-based study. SAGE Open. 2020;10(1):1-9. 
39. Alam Z, Higuchi M, Sarker MAB, Hamajima N. Mass media exposure and childhood diarrhea: a secondary analysis of the 2011 Bangladesh demographic and health survey. Nagoya J Med Sci. 2019;81(1):31.

40. Khan MN, Harris ML, Loxton D. Modern Contraceptive Use Following an Unplanned Birth in Bangladesh: An Analysis of National Survey Data. Int Perspect Sex Reprod Health. 2020;46((2020):77-87 2019.

41. Rahman MA, Khan MN, Akter S, Rahman A, Alam MM, Khan MA, Rahman MM. Determinants of exclusive breastfeeding practice in Bangladesh: evidence from nationally representative survey data. PLoS One. 2020;15(7): e0236080.

42. Ojo OB, Lougue S, Woldegerima WA. Bayesian generalized linear mixed modeling of tuberculosis using informative priors. PLoS One. 2017;12(3): e0172580.

43. Van de Schoot R, Kaplan D, Denissen J, Asendorpf JB, Neyer FJ, Van Aken MA. A gentle introduction to Bayesian analysis: applications to developmental research. Child Dev. 2014;85(3):842-60.

44. Huda FA, Chowdhuri S, Robertson Y, Islam N, Sarker BK, Azmi AJ, Reichenbach L. Understanding unintended pregnancy in Bangladesh: country profile report. Dhaka: International Centre for Diarrhoeal Disease Research; 2013.

45. Islam N, Islam MT, Yoshimura Y. Practices and determinants of delivery by skilled birth attendants in Bangladesh. Reprod Health. 2014;11(1):86.

46. Khan MN, Harris ML, Shifti DM, Laar AS, Loxton D. Effects of unintended pregnancy on maternal healthcare services utilization in low-and lowermiddle-income countries: systematic review and meta-analysis. Int J Public Health. 2019;2019(64):743-54.

47. Gross K, Alba S, Glass TR, Schellenberg JA, Obrist B. Timing of antenatal care for adolescent and adult pregnant women in South-Eastern Tanzania. BMC Pregnancy Childb. 2012;12(1):16.

48. Kost K, Landry DJ, Darroch JE. Predicting maternal behaviors during pregnancy: does intention status matter? Int Fam Plan Perspect. 1998;1998: 79-88.

49. Roy TK, Singh BP. Correlates of unwanted births in Bangladesh: a study through path analysis. PLoS One. 2016;11(10):e0164007.

50. Hall JA, Barrett G, Phiri T, Copas A, Stephenson J. Prevalence and determinants of unintended pregnancy in Mchinji District, Malawi; using a conceptual hierarchy to inform analysis. PLoS One. 2016;11(10):e0165621.

51. Exavery A, Kanté AM, Hingora A, Mbaruku G, Pemba S, Phillips JF. How mistimed and unwanted pregnancies affect timing of antenatal care initiation in three districts in Tanzania. BMC Pregnancy Childb. 2013;13(1):35.

52. Ministry of Health and Family Welfare. HRH Data Sheet 2014 of Ministry of Helath and Family Welfare. Dhaka: Ministry of Helath and Family Welfare; 2014.

53. Kyei NN, Campbell OM, Gabrysch S. The influence of distance and level of service provision on antenatal care use in rural Zambia. PLoS One. 2012; 7(10):e46475.

54. Akowuah JA, Agyei-Baffour P, Awunyo-Vitor D. Determinants of antenatal healthcare utilisation by pregnant women in third trimester in peri-urban Ghana. J Trop Med. 2018;2018:1673517.

55. Muchie KF. Quality of antenatal care services and completion of four or more antenatal care visits in Ethiopia: a finding based on a demographic and health survey. BMC Pregnancy Childb. 2017;17(1):300.

56. Chama-Chiliba CM, Koch SF. Utilization of focused antenatal care in Zambia: examining individual-and community-level factors using a multilevel analysis. Health Policy Plan. 2013;30(1):78-87.

57. Babalola SO. Factors associated with use of maternal health services in Haiti: a multilevel analysis. Rev Panam Salud Publica. 2014;36:1-09.

58. Osman FA. Health policy, programmes and system in Bangladesh: achievements and challenges. South Asian Surv. 2008;15(2):263-88.

59. Planning Commission, Bangladesh. Seven Five -Year Plan (2016-2020). Dhaka: Bangladesh planning commission, Ministry of Planning; 2016.

60. Chowdhury AMR, Bhuiya A, Chowdhury ME, Rasheed S, Hussain Z, Chen LC. The Bangladesh paradox: exceptional health achievement despite economic poverty. Lancet. 2013;382(9906):1734-45.

61. Save the Children. The status of community based health workers in rural Bangladesh. Dhaka: Save the Children; 2011.

62. Bangladesh Rural Advancement Committee. BRAC annual report 2012 Dhaka: BRAC; 2013.

63. Ahmed SM, Hossain MA, RajaChowdhury AM, Bhuiya AU. The health workforce crisis in Bangladesh: shortage, inappropriate skill-mix and inequitable distribution. Hum Resour Health. 2011;9(1):3.
64. Ahmed SM, Evans TG, Standing H, Mahmud S. Harnessing pluralism for better health in Bangladesh. Lancet. 2013;382(9906):1746-55.

65. United Nations Children's Fund. Understanding urban inequalities in Bangladesh: a prerequisite for achieving vision 2021. Dhaka: United Nations Children's Fund; 2010.

66. Yaya S, Bishwajit G, Ekholuenetale M, Shah V. Awareness and utilization of community clinic services among women in rural areas in Bangladesh: a cross-sectional study. PLoS One. 2017;12(10):e0187303.

\section{Publisher's Note}

Springer Nature remains neutral with regard to jurisdictional claims in published maps and institutional affiliations.
Ready to submit your research? Choose BMC and benefit from:

- fast, convenient online submission

- thorough peer review by experienced researchers in your field

- rapid publication on acceptance

- support for research data, including large and complex data types

- gold Open Access which fosters wider collaboration and increased citations

- maximum visibility for your research: over $100 \mathrm{M}$ website views per year

At BMC, research is always in progress.

Learn more biomedcentral.com/submissions 